\title{
Public Service Media in the Age of Social Networks
}

\author{
Rita GLÓZER \\ University of Pécs \\ Pécs, Hungary \\ e-mail: glozer.rita@pte.hu
}

\begin{abstract}
Digital transformation and the expansion of social networks have essentially modified journalistic practice, facing challenges concerning its essential operation and boundaries. The traditional business models have collapsed, young people's media consumption habits have changed, and more non-professional journalists participate in news production. Social media platforms have an immense effect on journalistic work, especially journalists' professional and ethical standards. Perhaps traditional public service media are the ones that stand the farthest away from participatory practices and platform logic, characterizing today's media environment. What are the public media services' opportunities to fulfil their commitment of authentically and objectively informing citizens, including young people, about public affairs? This study aims to picture the boundary work of journalism currently underway by reviewing the phenomena emerging on the border of journalism and social media. Additionally, the study attempts to answer what a successful social media strategy looks like in public service media by presenting the social media activities of "tagesschau”, the newsmagazine of ARD, a German public-service channel.
\end{abstract}

Keywords: journalism, public service media, social media, digitalization, Instagram, tagesschau

\section{Journalism in the Age of Social Media}

The determining tendencies of the current media environment significantly impact the whole economy of news production and consumption and journalism as a profession indirectly. Due to the expanding processes of digitalization and convergence (Jenkins, 2006), the popularity of social media has increased. Platformization affects every aspect of life (van Dijck-Poell-de Waal, 2018). News consumption is increasingly occurring online, often through social media, embedded 
in everyday media consumption. At the same time, media consumption is also becoming unbound from time and space and increasingly adapting to user demands with the spread of portable smart devices.

In the late 1990s, when the impact of emerging digital technologies on journalism started to become perceptible, experts greeted this process. They projected implications like broadening interactivity, customizability, multimediality, and the potential to build new communities with optimistic expectations (Perreault-Ferrucci, 2020). Also, this initial optimistic approach expected the broadening technological convergence to eliminate the factors restricting the news industry. This way, the journalistic and everyday forms of news distribution, such as conversation, rumour, or private letters, will converge (Burgess-Hurcombe, 2019: 360). However, professionals also had to face the dangers and risks of this process soon, e.g. digitalization has radically transformed the relationship between journalists and their audiences and sources. It has transformed all the areas of journalistic work, from news gathering to editing and producing news and publication (Burgess-Hurcombe, 2019; Vázquez-Herrero, Direito-Rebollal-López-García, 2019; Nah-Chung, 2020). The conventional media genres, the traditional storytelling methods and news narratives are disappearing, and they are perceived differently (Carlson-Lewis, 2015; Boesman-Costera Meijer, 2018). New technological solutions supplement the old journalistic toolbox (Pavlik-Bridges, 2013), seriously affecting media organizations and their business models. Changes have begun in newsroom structures, new positions have emerged (such as social media manager or comment moderator), and new types of legal and ethical issues have arisen.

Accordingly, technological development is threatening both the external and the internal boundaries of journalism as a profession and an activity, and many researchers interpret the resulting transformation as boundary work or even boundary struggle (Carlson-Lewis, 2015; Boesman-Costera Meijer, 2018). In academic discourse, new concepts have been established to describe the changes consisting of various elements and to name the new developments, focusing on some aspects of the transformation by narrowing the concept of journalism with various attributes. This study will review the complex relation network of journalism and social media and the opportunities of public service media in the present situation with the help of these terms below.

The frequently mentioned concept of digital journalism comprehends intentions and solutions emerging these days concerning convergent digital media technology for journalistic purposes. According to Burgess and Hurcombe (2019: 360), digital journalism includes "those practices of news gathering, reporting, textual production and ancillary communication that reflect, respond to, and shape the social, cultural and economic logics of the constantly changing digital media environment". Indisputably, the change of media technology itself is a significant starting point of the digitalization of journalism. That is why a technology-focused definition seems obvious, but this approach does not seem to be well-established 
anymore because digitalization is widely spread. A technology-based explanation cannot be valid because digital journalism "has been everybody's business in the sense that it is of interest to a range of social sciences, humanities and even sciences and technology disciplines" (Burgess-Hurcombe, 2019: 359), and not even the self-definition of journalists is based on this. According to Perreault and Ferrucci (2020), the attribute "digital" has essentially three meanings: "utilising technology to tell stories", "disseminating information in the quickest way possible", and focusing "on the audience in a market-driven manner" (Perreault-Ferrucci, 2020: 1305). However, there are divergences between digital and legacy journalism concerning the technological devices (laptops, tablets, smartphones, digital voice and video recorders, drones, virtual reality), the communication channels (email, blogs, self-publishing tools), and the activities (data-driven digital storytelling, data visualization, digital video, and new digital ways of news gathering, interviewing, and documenting). Still, those concerned do not look at the application of new technologies as the main criteria of digital journalism (Perreault-Ferrucci, 2020). They consider technology instead as a simple, trivial resource of professional work.

The digital media environment also dramatically impacts the production process of journalistic content, both in terms of language (in the broad sense) and genres. Salaverría (2019) emphasizes the role of hypertext, multimedia and transmedia, and interactivity among the linguistic features of digital journalism, which he states are the determining features of online news production, otherwise present in other types of media as well. As the term social news suggests, social media play an essential role in transforming traditional genres by their characteristic style and means of expression. According to Burgess and Hurcombe (2019), this distinctive genre of digital journalism is distinguished "by a fluency in the vernacular conventions and pop-culture sensibilities of social media: that is, the acronyms, the memetic imagery, and the affective use of GIFs (frequently depicting celebrities) are common in platform cultures" (Burgess-Hurcombe, 2019: 363).

News production is getting closer to popular culture, but it is not the only implication of its interconnectedness with social media. The young audiences available on social media platforms, who are especially receptive to advertising, branding, and online marketing technologies, represent an increased value for digital journalism (Perreault-Ferrucci, 2020: 1307). Therefore, the news economy is also exposed to the effects of commercialization related to the spread of content marketing and participatory marketing (Nyírő-Csordás-Horváth, 2012) or the activities of social influencers, for instance. Specific fields of journalism, such as "fashion and lifestyle journalism", which is considered soft news, have become twilight zones where amateur bloggers and vloggers increasingly supplement professional journalists. As is conclusive from Maares and Hanusch (2018), there is no significant difference among Austrian and German micro-bloggers between amateur bloggers and professional journalists. Their value systems, goals, and 
perception of roles in the twilight zone mentioned above undergoes a so-called hybridization, as "traditional journalists are moving more toward the activities of micro-bloggers” (Maares-Hanusch 2018: 13).

\section{Social Media as a Field of Journalism?}

The involvement of amateur users in media content production was one of the determining antecedents to social media sites becoming fields of journalism. Users become determining actors of the information and media economy due to the texts, photos, and videos they make and share on their social media sites or because they are commenting, sharing, transmitting, evaluating, and curating activities. In the mid-2000s, the fathers of the participatory culture theory (Jenkins, 2006; Bruns, 2008) and their followers (e.g. Burgess-Green, 2009) presented the struggles of everyday users for their rights in participatory processes as efforts to democratize and diversify media economy as a whole. A decade later, it was clear that voluntary content producers were doing unpaid work for the owners of great media platforms, and the power asymmetry between producers and users was increasing in opposition to the excessive expectations. Furthermore, the specific internal algorithmic logic of the new media platforms has a severe impact on the media system and other social systems (van Dijck-Poell, 2013). At the same time, participatory logic has expanded to several areas of science and culture (participatory theatre, participatory action research, participatory museum). The common feature in the efforts emerging in these diverse areas is to empower or amplify marginalized, low-status, disadvantaged social groups, include them in social actions, and present their viewpoints, opinions, and knowledge. Those who stand for the participatory approach aim to eliminate power asymmetries and inequalities they consider undue and harmful and indirectly reshape public awareness.

One of the areas affected by participatory culture is journalism. The concept of participatory journalism refers to different forms of reader input at all stages of news production (Singer et al., 2011). In recent years, contemporary forms of audience contribution, such as citizen media, citizen blogs, citizen stories, collective interviews, comments, content hierarchy, forums, journalist blogs, polls, and social networking, have become increasingly integrated into the news production processes of online newspapers and websites (Singer et al., 2011: 17). Although the process is somewhat contentious (Carlson-Lewis, 2015; Jurrat, 2011; Salaverría, 2019), it can be interpreted as a consequence of journalists' effort "to accommodate input from the audience within the spaces that media institutions once tightly controlled" (Singer et al. 2011: 18). The term amateur journalism highlights that people without professional education and out of the 
scope of institutional arrangements can also enter the area of the journalistic profession, which otherwise would require corresponding educational background and institutional system. From a professional point of view, anxieties arise from the lack of knowledge of ethical and professional standards and taking responsibility concerning the activity of amateur journalists (Jurrat, 2011). Content produced by amateur journalists may also deceive the audience, as members of the audience who are used to high-quality professional journalistic content may not be aware that the factual basis, objectivity, credibility, and fairness is not guaranteed by professional standards and institutional assurances associated with professional journalism.

The concept of citizen journalism - linked to the tradition of critical social theory - synthesises the participation of citizens interested and engaged in public affairs in the practice of journalism. Nah and Chung (2020) consider civil or citizen journalism (regarded as a type of participatory journalism) as the recent development of a long process and primarily approach it from the perspective of the internal processes of journalism. The authors' starting point was that professional journalists within legacy media consider citizens as passive audiences and rarely treated them as news sources. They dated the trend shift to the 1980s, when journalists started to pay increasing attention to the audience already seen as news sources and made efforts to get citizens to speak in news stories, so they increasingly became active participators in news production by producing their own news stories or by active collaboration with journalists. From this perspective, citizen journalism also has a significant role in the development of civil society (Nah-Chung, 2020: xiv) by urging citizens to deliver their opinion concerning community issues and public affairs.

Another related concept, citizen witnessing, reflects on situations in which everyday people produce news stories as witnesses to important or dramatic occasions or events of great interest (Stuart, 2013). Allan describes accidental journalism "as a type of first-person reportage in which ordinary individuals temporarily adopt the role of a journalist in order to participate in newsmaking, often spontaneously during a time of crisis, accident, tragedy or disaster when they happen to be present on the scene" (Allan, 2013: 9). In our days, the most likely contributions of those accidental, amateur journalists are video footages, smartphone photographs shared via social networking sites, or even social media posts.

The twilight zone between digital journalism and online activism broadens by the increasing participation of everyday users in digital news production and distribution. The concept of protest journalism refers to the social media publication of photos taken and videos made by participants about various protests, riots, and clashes. For media research, this type of digital content production raises several problems, e.g. archiving. Although media content (such as Snapchat 
footages) with pre-programmed disappearance, synchronous coverages made by witnesses and delivered widely are meaningful media representations of socially significant events, they cannot be archived due to their ephemeral nature (VázquezHerrero-Direito-Rebollal-López-García, 2019), which is a great loss for collective memory. Consequently, media researchers face severe methodological and ethical challenges considering precariousness, privacy, and platform affordances (Richardson, 2020).

According to Atton and Hamilton (2008), the term alternative journalism is an ageless and ever-changing effort or practice with the specific goal of responding critically to the predominant concepts of journalism. In the frameworks of network society, this includes the journalistic-natured activities of amateur users outside the institutional system of the professional news industry and independent from the journalistic profession, using the potentials of network media. In the late 2000s, several major media theories (e.g. Burns, 2008; Castells, 2009; Jenkins, 2006) included the idea that social sites may become the effective alternative to mainstream media, as Poell and Borra point out (2011). Political activists often join such alternative communication platforms because creating their communication channels and their public sphere has always been a challenge for them, and social sites seemed convenient for these purposes. So, the concept of alternative journalism "includes the media of protest groups, dissidents, and fringe political organisations" and "can be seen as an attempt to counterbalance the dynamic of mainstream reporting” (Poell-Borra, 2011: 698).

Analysing the amateur news content posted on the social media sites Twitter, YouTube, and Flickr by civil participants in the protests around the 2010 G20 Summit in Toronto, Poell and Borra (2011) concluded that political activists primarily use this opportunity of the alternative report. Although these organizations urged protestors to "broadcast breaking news" on their social media sites (PoellBorra, 2011: 696), as the authors had indicated, the mobilization of everyday users was less successful, and "the social media did not facilitate the crowd-sourcing of alternative reporting" (Poell-Borra, 2011: 695). According to the research, the attractiveness of the public-political-flavoured alternative media is somewhat restricted. It serves as an attractive alternative for communication only for the groups that emerged due to specific issues or situations, but it remains only a mere possibility for the mass news production and distribution by everyday people. In addition to the terms discussed above, the following terms are often used to describe hybrid forms of digital media journalism: grassroots journalism, opensource journalism, hyperlocal journalism, networked journalism, and social media journalism. The latter highlights one of the most recent trends in the transformation of journalism.

Social media journalism is justified mainly because social media has recently become the primary location for accessing news. According to Reuters Institute 
Digital News Report 2020, "across all countries, just over a quarter (28\%) prefer to start their news journeys with a website or app. Those aged 18-24 (so-called Generation Z) have an even weaker connection with websites and apps and are more than twice as likely to prefer to access news via social media. Across age groups, use of Instagram for news has doubled since 2018 and looks likely to overtake Twitter over the next year" (Newman et al., 2020: 11).

As social media platforms have become effective newsreels, audience members get to the news through them using mobile devices, and news consumption is part of their everyday media consumption. This process has several dangerous consequences, most notably that "journalists no longer control access to information, while greater reliance on social media and other platforms give people access to a wider range of sources and alternative 'facts', some of which are at odds with official advice, misleading, or simply false" (Newman et al., 2020: 10). The determinant role of social media in news consumption has also changed the way users inform themselves, as their awareness is accidental, incidental, and unbalanced due to the news they are exposed to, which are programmed by the algorithms of social media platforms; meanwhile, users themselves feel well-informed (VázquezHerrero-Direito-Rebollal-López-García, 2019).

News media are also forced to be present on these platforms to reach their readers, and this also brings journalists to use social media actively (including selfbranding techniques that are typical here) (Djerf-Pierre-Ghersetti-Hedman, 2016), and they are urged to comply with the popular social media genres and to adapt themselves to those. Thus, it is becoming increasingly common to find that native social media formats are being transformed into journalistic micro-formats such as in the case of Instagram Story or TikTok videos. The journalistic adaptation of these social media genres with a short lifespan brings unprecedented ephemerality to the field of professional news production as well (Vázquez-Herrero-DireitoRebollal-López-García, 2019).

In news consumption, and subsequently in news production, "social media logic" (van Dijck-Poell, 2013) takes the place of "mass media logic” (VázquezHerrero-Direito-Rebollal-López-García 2019: 2), validating its standards, strategies, mechanisms, and economies. Social media has recently become the scene of the cultural production of news as well. As the use of social sites is getting integrated into the daily work routine of journalists, the technical features have a normalizing effect on journalism, both on its professional standards and everyday activities (Hermida-Mellado, 2020). As users increasingly prefer partially or fully visual content within social media consumption, this trend is spilling over to the field of journalism, and a similar tendency is also apparent in the case of podcasts (Newman et al., 2020: 28, 30).

Reaching younger generations is a challenge for news media because of this generation's general apolitical nature and media consumption habits. In the media 
consumption patterns of generation $\mathrm{Z}$ and younger people, television and especially printed media are neglected, and the popularity of social sites is outstanding even among online sources. Although Facebook and YouTube still lead the ranking of social networks based on the number of users according to the July 2021 figures $(2,853$ billion and 2,291 billion users), Instagram, fit for sharing pictures and short videos, is in fourth place with 1,386 billion users. ${ }^{1}$ Whereas $12 \%$ of Facebook users under the age of 25 are women and $17 \%$ men, and in the age-group of 25-34 women are $12 \%$ and men $18.8 \%, 29.9 \%$ of Instagram users are aged between 18 and 24, and a further $32.1 \%$ are aged between 25 and 34 . This means that $60 \%$ of the Instagram users are young adults compared to the $24 \%$ and $26 \%$ of Facebook. TikTok, another trendy application among people even younger globally, currently has 732 million users, from which exactly a quarter is between 10 and 19, and a further 44\% are aged between 20 and 29 and 30 and 39 (each share half approximately). It seems to be clear from the figures above that the social applications Instagram and TikTok have a higher rate of young people and young adults among their users than Facebook, even if the latter has a more significant number of users than the upstarting apps. As the recent June 2021 Statista research points out, "younger adults were more likely to use social media as a way to access news, as 34 per cent of consumers aged under 35 used social media for news, compared to 26 per cent of all adults". ${ }^{2}$ Consequently, news media can reach primarily the younger generations through the social sites they prefer.

\section{Public Service Media in the Age of Social Media}

The place and role of public service media have become dubious and uncertain (Lowe et al., 2017) within the framework of the network society (Castells, 2005). The original goal was to inform, educate, and entertain citizens, incorporated in the comprehensive efforts to maximize political authority and emancipate citizens. Public service media carried out this work with government support within the national framework in a traditional top-down monologue. However, the bottom-up logic of the global network media system favours neither state involvement nor the operation within a national framework.

In recent years, critiques concerning the operation of the large social networks that have played a crucial role in the emergence of the network society and the global companies owning them target the drawbacks of "participatory culture" discussed above, the exploitation of users (Fuchs, 2014), the monitoring of them, the misuse of the data collected this way, and the positioning of new media platforms outside of social standards and rules (van Dijck-Poell-de Waal, 2018;

1 https://www.statista.com/statistics/272014/global-social-networks-ranked-by-number-of-users/.

2 https://www.statista.com/statistics/281915/main-news-sources-millennials/. 
Lowe et al., 2017). According to critics, "the heart of the networked society rationale is essentially economic, rather than democratic, cultural or social" (Lowe et al., 2017: 23). Accordingly, these platforms are not engaged with the public interest, the common good, and public affairs - that is to say, traditional public service values. At the same time, their attractiveness is increased by, among other things, the customizability and individual nature of the services and content they offer, the publication of user content, and the providing of on-demand access instead of linear content service - all features that are unknown in traditional public service media. For all these reasons, public service media are being increasingly marginalized these days. The question is sharp: are they able to address citizens, especially young people, in a convergent, digital media environment, amid the boundary struggle of journalism and the competitions with start-ups and platform giants.

\subsection{Tagesschau - Public Service in Digital Media}

All news media are trying to react to the increasing role of social sites in news consumption in one way or another: they are experimenting with various solutions without any tested or proven strategy. In the following, this study will present an innovative model of one of Europe's powerful public service news brands, the German tagesschau. The data and information partly come from the analysis of the content published on different digital accounts of the channel and partly from an interview with Patrick Weinhold, ${ }^{3}$ Leading Editor and Head of Social Media at ARD-Aktuell.

Tagesschau is a news brand of ARD, a broadcaster established by the joint organization of Germany's regional public service broadcasters. ARD, founded in 1950 as a television network, has broadcasted its first daily news feature on the television channel Das Erste (Channel One) from Hamburg since 1952. After the launch, the live news programme was initially broadcasted only once a day, and from the 1960s onwards, there were morning and evening editions. Since 1992, news magazines have been shown in the morning (MOMA - Morgenmagazin) and in the evening (tagesthemen), short news every half hour between 5.30 and 8.30 in the morning and finally a night news show (nachtmagazin). However, the

3 The interview and research of reference sources took place within the frameworks of the research and curriculum development project NEWSREEL2 - New Teaching Fields for the Next Generation of Journalists (2020-1-HU01-KA203-078824) supported by ERASMUS+. The project consortium consists of media and journalism scholars from the University of Pécs (Hungary), Masaryk University (Brno, Czech Republic), the Erich Brost Institute for International Journalism, an affiliate institute of TU Dortmund University (Germany), the ISCTE - University Institute of Lisbon (Portugal), and the University of Bucharest (Romania). The project has a solitary "journalism practice” partner - host writer, an international network based in Berlin. https://newsreel.pte.hu/. 
channel is also actively present in the digital sphere: the digital news channel tagesschau $24^{4}$ broadcasts live news content $0-24$, and their news materials are available on their website, ${ }^{5}$ mobile application, ${ }^{6}$ and independent third-party platforms. Three hundred employees contribute to content production today. According to the organization's blog, " "The tagesschau is the oldest and mostwatched news program on German television", and Patrick Weinhold adds that it is also an essential part of Germany's cultural heritage in a sense. According to Statista.com, the television news brand with a determining role on the entire German media market had an average of 11.78 million viewers in $2020 .^{8}$

However, the television news programme's audience is quite old: the average age of tagesschau late-night news show viewers is currently 64 years. It is difficult under these circumstances to fulfil the public service tasks of informing the entire German public (including young people) about public affairs and politics. The absence of certain citizens from news consumption groups means a severe challenge to public service media since being adequately informed is a prerequisite for making responsible individual decisions. Ten years ago, the management of tagesschau started to look for solutions to reach young people through the increasingly popular digital media and social networks. At this time, in 2012, Patrick Weinhold joined tagesschau, and he is now managing the work of the social media department as editor-in-chief. Parallel to the establishment of the social media department, resources for communication in the digital sphere have continuously increased; journalists are now devoting their digital media competence and knowledge to digital and television content at a rate of $50-50 \%$, which was $20-80 \%$ ten years ago (20\% for digital sphere and $80 \%$ for television).

The social media department, currently consisting of 16 journalists, has implemented the digital transformation of the TV brand to a 360-degree brand in the past ten years. ${ }^{9}$ In the early 2010 s, when the audience's news consumption expectations were remarkably changing, while the popularity of social sites increased, tagesschau developed its digital strategy. The aim was to create news products that young people would happily consume. While other actors of the German media market have created new, trendy, and youthful brands independent of their original brands, especially to reach the young audiences, tagesschau's staff

4 "tagesschau24 is the digital news channel of the ARD. It features the news content of the tagesschau. Currently the programme airs from 9 a.m. to 8 p.m. every day. The broadcast is produced by the news division ARD-aktuell in Hamburg. tagesschau24 offers its viewers key stories from politics, business, arts, and sports. In interviews throughout the day, our correspondents as well as experts from different fields analyse current events." https://blog.tagesschau.de/uber-uns/about-us-en/.

5 https://www.tagesschau.de/.

6 https://www.tagesschau.de/app/.

7 https://blog.tagesschau.de/uber-uns/about-us-en/.

8 https://www.statista.com/statistics/410911/tagesschau-tv-reach-in-germany/.

9 The main goal of the 360-degree branding is to reach audience members in consistent but multiple ways. 
did not change the core brand but kept it and started to build up a social media news production based on it. Ultimately, this turned out to be a good and crucial decision. The essence of their strategy is to produce news for various digital channels and platforms, always in line with the specificities of the specific platform.

They have accounts and publish news content on Facebook, ${ }^{10}$ YouTube, ${ }^{11}$ Twitter, ${ }^{12}$ Instagram, ${ }^{13}$ and TikTok. ${ }^{14}$ The German news brands have the most subscribers on these social networks, and their website has the fifth most users among similar German news pages. This success is partly because, as early adopters, they were the first among the German news media to have created these accounts and started publishing content there. Instagram proved to be similarly successful in reaching young people, and they are now pioneers on the increasingly popular TikTok platform, where tagesschau was the first news media to create an account. ${ }^{15}$

Regarding the pitfalls and difficulties of the project, Patrick Weinhold pointed out that it was not a simple task to present reliable, credible, and factual news on platforms that were initially designed for other purposes (video-sharing social site, social network, image-sharing social application, microblog) and used algorithms that control them to favour popular content. Producing news for different platforms requires strong differentiation; Instagram, e.g., focuses on storytelling and visual aesthetics that define its platform, a static application based on posting images. Meanwhile, TikTok, used for video-sharing by the youngest users, addresses topics of interest to this young age group.

If we wish to explore the components and reasons behind their successful presence in the digital sphere, it is worth highlighting the efforts and resources devoted to producing social media news across the entire organization. One of the primary conditions of efficient digital content production is to provide the human and financial resources needed: tagesschau - as seen above - established a separate social media department about ten years ago, headed by a young manager with a background in the field, Patrick Weinhold. Besides journalists, the social

10 https://www.facebook.com/tagesschau - more than 2 million people follow the account, where fresh news feeds are published several times an hour, directing readers to the website.

11 https://www.youtube.com/user/tagesschau - they have had a channel since 2006 and currently have one million subscribers. The news programme broadcasted at $8 \mathrm{pm}$ is uploaded to this platform daily.

12 https://twitter.com/tagesschau - they have joined in 2007 and currently have about three million followers. Here, adapting to the features of the platform, short visual news are published several times an hour, which direct the reader to the website.

13 https://www.instagram.com/tagesschau/ - 3.3 million followers read their news content here.

14 https://www.tiktok.com/@tagesschau - with 915,000 followers.

15 Weinhold pointed out in the interview that their appearance on TikTok was met uncomprehendingly within the industry, but he and his team realized that the number of young people, also from Germany, is increasing on this platform, and content is produced for them by various influencers. However, this content is often wrong, inaccurate, and misleading. Influencers, uneducated and amateur in news service, cannot explain and interpret the news to young people, which can be dangerous. Therefore, the tagesschau staff decided to create their news channel there also. 
media team also includes staff with expertise in visual content production: graphic designers, graphic editors, and motion designers. Within the social media department, a so-called "innovation laboratory" supports the work of the staff covering daily content production. The task of the staff here is to monitor new formats and trends emerging in social media and create new, experimenting prototypes based on them. The most regularly used formats or social media news genres are selected from these. Constant development and innovation in genres and formats is an integral part of adapting to the characteristics of platforms. Another prerequisite of the up-to-date operation is the constant monitoring of the social media environment, gathering and analysing data about media usage and consumption habits, and making strategic decisions. Data are partly sourced by the tagesschau staff from the platforms themselves (using the insight function) and partly in collaboration with the media researchers at the University of Hamburg, thus successfully drawing on resources from the academic sphere.

Another critical component of successful news content production is related to the formats mentioned above. The popularity of news content produced for different social media platforms depends not only on the formal compatibility with the platform's characteristics (e.g. the use of the corresponding aspect ratio or a typical storytelling style) but also on the use of more or less constant, identifiable formats. The staff of the so-called innovation laboratory have created a manual with a detailed description of the currently used formats, and they are updating it continuously. The manual also supports them with explaining step by step how to use properly, for example, the image editor Photoshop when creating a specific format. The application of such ready-made editing formats facilitates the work of journalists, as while selecting from the various formats, they can decide which the most appropriate one is to produce the news for a given audience on a given platform. The use of temporarily permanent formats is also helpful from the audience's point of view, as it provides a kind of uniformity and consistency and offers a reference point for the interpretation of content. Moreover, the most appropriate editing techniques result in quality and homogeneous content, essential for professional news production and social sites.

\subsection{Tagesschau on Instagram}

Since the audio-visual news production and storytelling regarding text and image resource combination is the most complex on Instagram and since it is also the most popular among young adults, this part of the study will outline tagesschau's innovative activities in social media journalism through Instagram.

The bio of the tagesschau news brand's Instagram account has the following introductory text: Nachrichten, Erklärungen und besondere Momente aus aller Welt. Das ist die tagesschau auf Instagram. 'News, explanations, and special moments 
from all over the world. This is the Tagesschau on Instagram.' The account with 3.3 million followers currently has 13,000 posts and publishes 5-8 posts and several stories daily. The creators use almost all the native functionalities of Instagram: one-page posts and posts with multiple elements, short videos published as posts, longer videos published in IGTV, stories with quizzes, stickers, emoticons and infographics, drawings and animated visual elements. A longer textual explanation usually supplements the published visual content, and hashtags are typical for the brand (\#tagesschau) and related topics. The Instagram account corresponds with the visual image of the tagesschau brand regarding its colours and style.

By examining the news content published in tagesschau's Instagram account, several components of their storytelling and news production strategy can be identified. First of all, using the formats mentioned above. "Text on photo" format is one of the permanent editing patterns Patrick Weinhold mentioned. It is a square photograph with little textual information on it, while the emphasis is on the photo itself, which effectively transmits the content of the news (figures 1-2). These photos also suit the distinctive visual culture of Instagram regarding their aesthetics and clean style (Manovich, 2007).

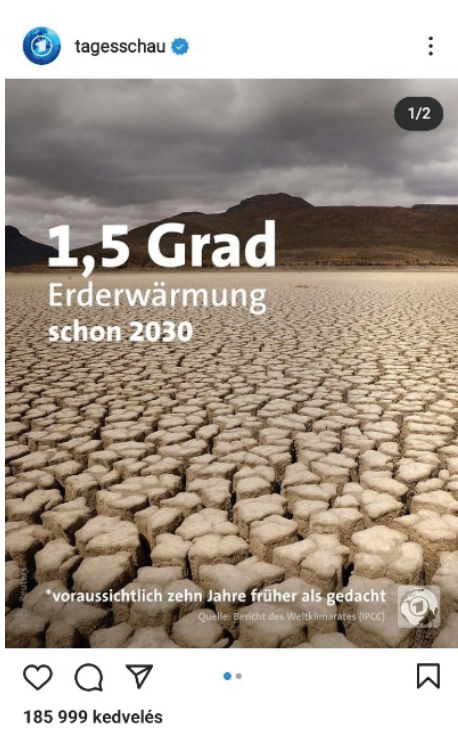

Figure 1. 1.5 Degrees

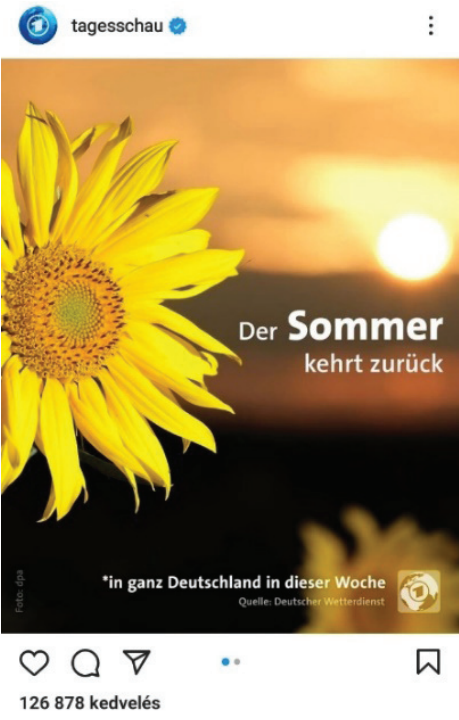

Figure 2. Summer returns

The genre "it happens at the same time" is an example of video formats produced in the split-screen mode in a 1:1 square format. It offers an excellent opportunity to present contrasts, oppositions, and contradictions by applying visual storytelling resources. This way, the same event can be presented from different perspectives, showing simultaneous actions and situations. 

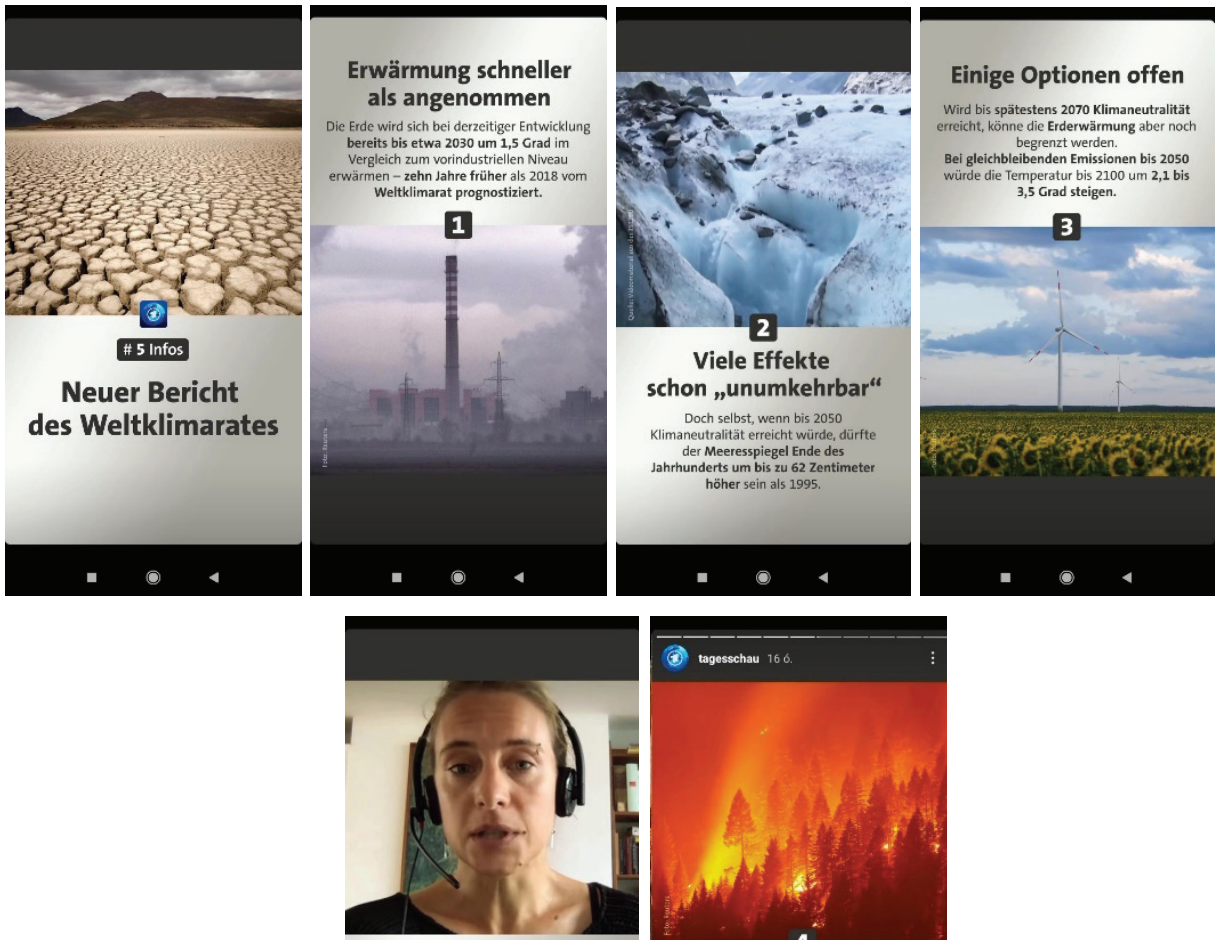

Viele Effekte schon "unumkehrbar" Doch selbst, wenn bis 2050 Klimaneutralitiăt erreicht würde, dürfte der Meeresspiegel Ende des höher sein als 1995
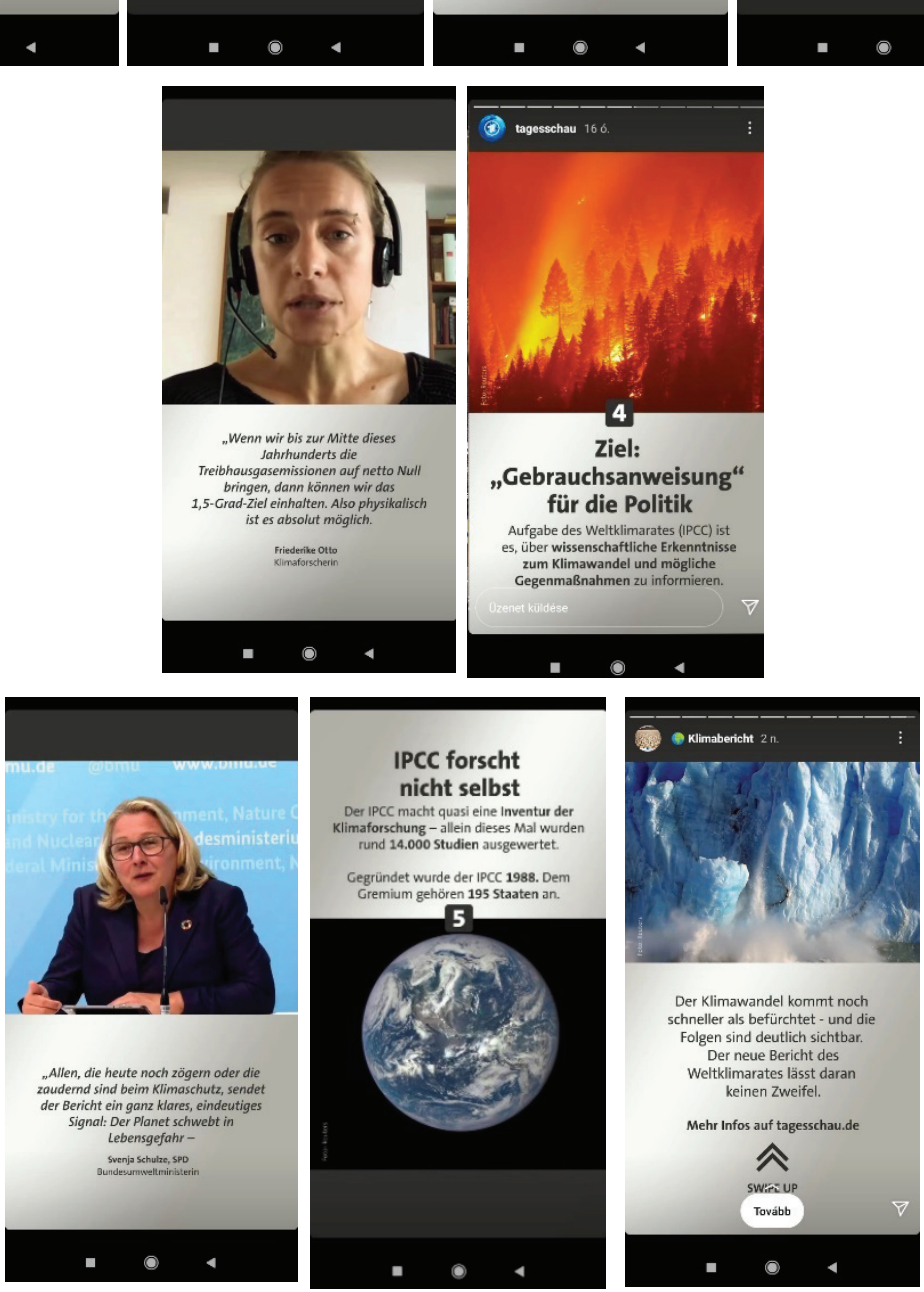

Figure 3. Climate change 
Also, the multi-element, serial nature, in general, is essential in the various methods of storytelling based on the use of photos, drawings, or infographics, i.e. static images. This serial nature comes in posts created by stitching together multiple images or Instagram Stories made up of multiple elements. Both types can be complemented by animated elements, video or audio materials. In the case of such content, the sequencing and logical arrangement of the images stitched together provide the organizing principle of the narrative, as can be seen in the series of images posted as an Instagram Story (Figure 3). Creators help identify narrative logic by numbering and typographic tools (font size, bolding, layout). Image editing provides the dynamics of storytelling based on variation, built on playing with similarity (in perspective or framing) and variation (alternating the placement of elements on the screen), still and moving images and animated elements.

Journalists tend to use various tools to structure information or highlight elements they want to emphasize to present a topic or news as effectively as possible and in a way that is compatible with the platform and the media consumption habits. On Instagram as a visual platform, infographics and other graphic solutions are also practical tools for this kind of interpretative structuring, as illustrated by the following examples (figures 4-6).

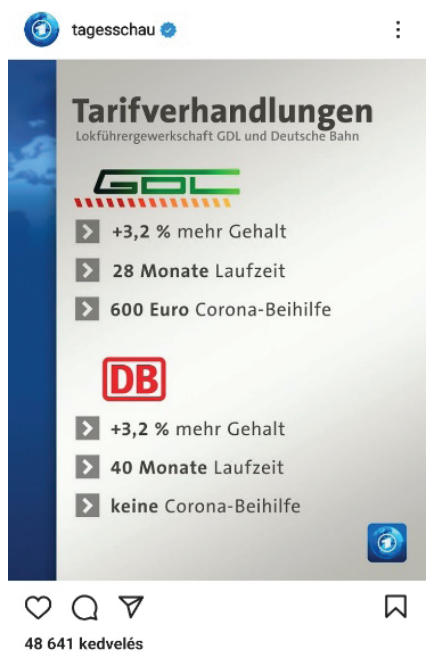

Figure 4.

Train drivers' union
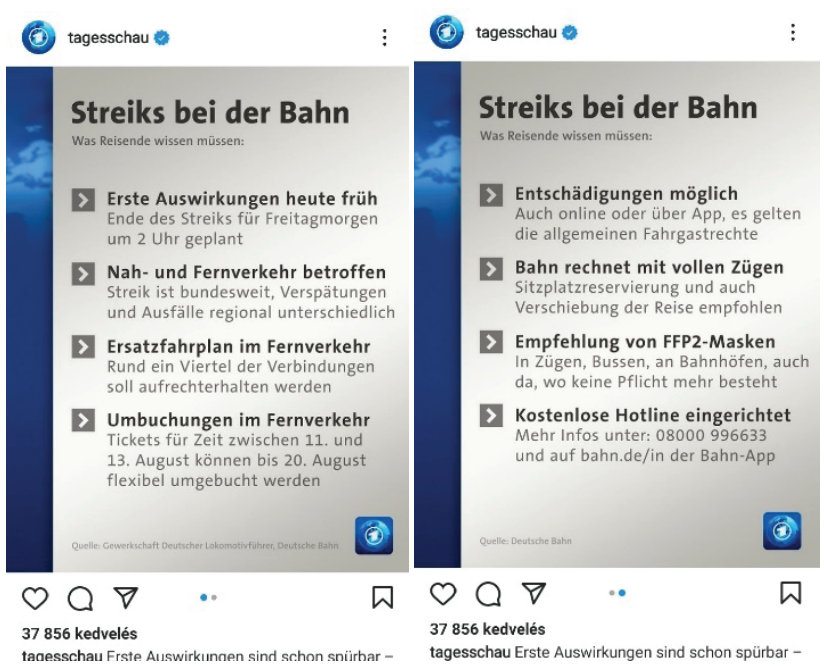

Figure 5. Strikes on the railways 


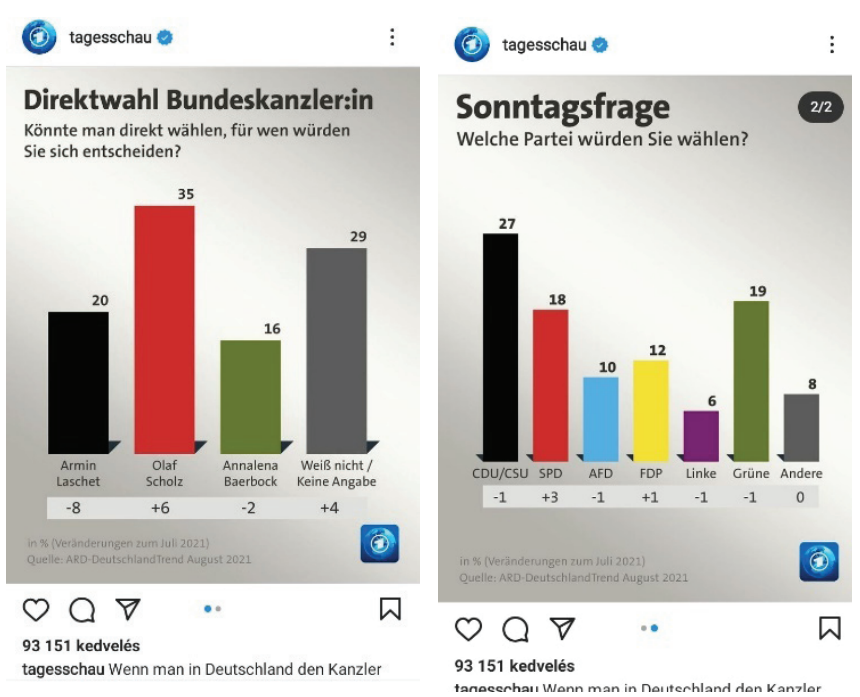

Figure 6. Direct election

In the practice of tagesschau, video journalists adding journalistic interpretative narratives to the information are a peculiar hybrid of the "talking heads" typical for traditional television culture, the figures of amateur video bloggers, and the influencers in social media. This solution brings back the function of the expert gatekeeper, who is otherwise missing from the amateur news content in social media, to maintain the light and casual style of the communication of social media influencers (Figure 7). It is worth noting that the journalists' age is in line with the audience's age on Instagram. Moreover, Instagram Stories use the same formats when citizens interpret or comment on a topic (Figure 8).
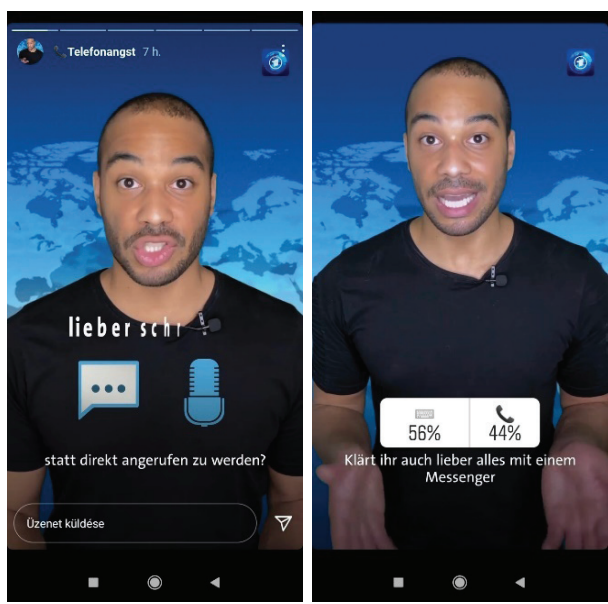

Figure 7. Anxiety about phoning

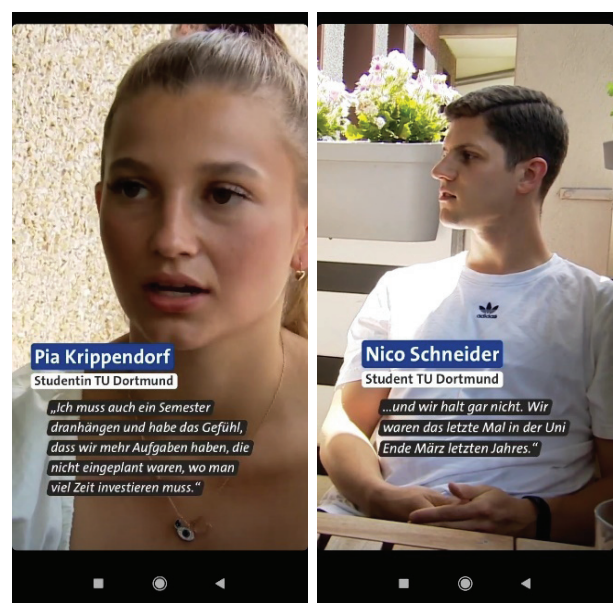

Figure 8. Krippendorf and Schneider 
Educating, informing, and sometimes sensitizing the audience on issues of public interest is a crucial task of public service media. In this regard, there are various solutions and formats in the repertoire of tagesschau. Multi-element posts on a complex issue often feature various experts, giving space to professional, scientific, or public knowledge (Figure 9).

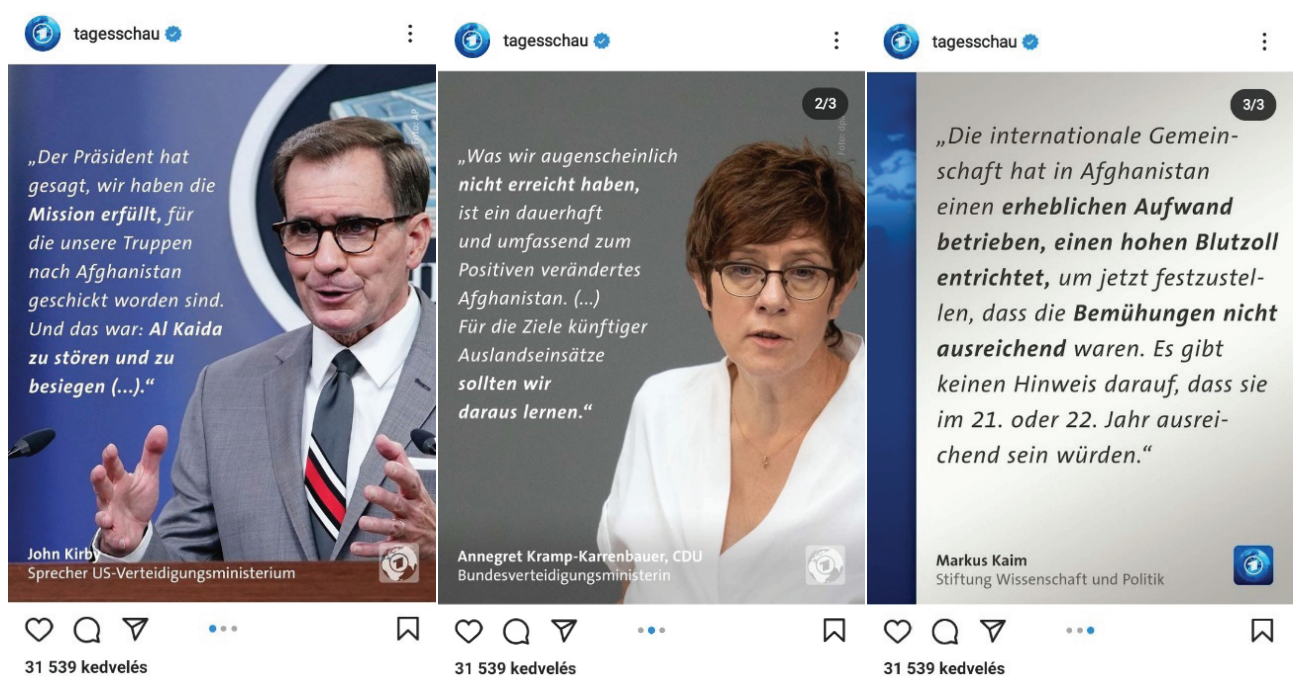

Figure 9. Kirb, Kramp-Karrenbauer, Kaim

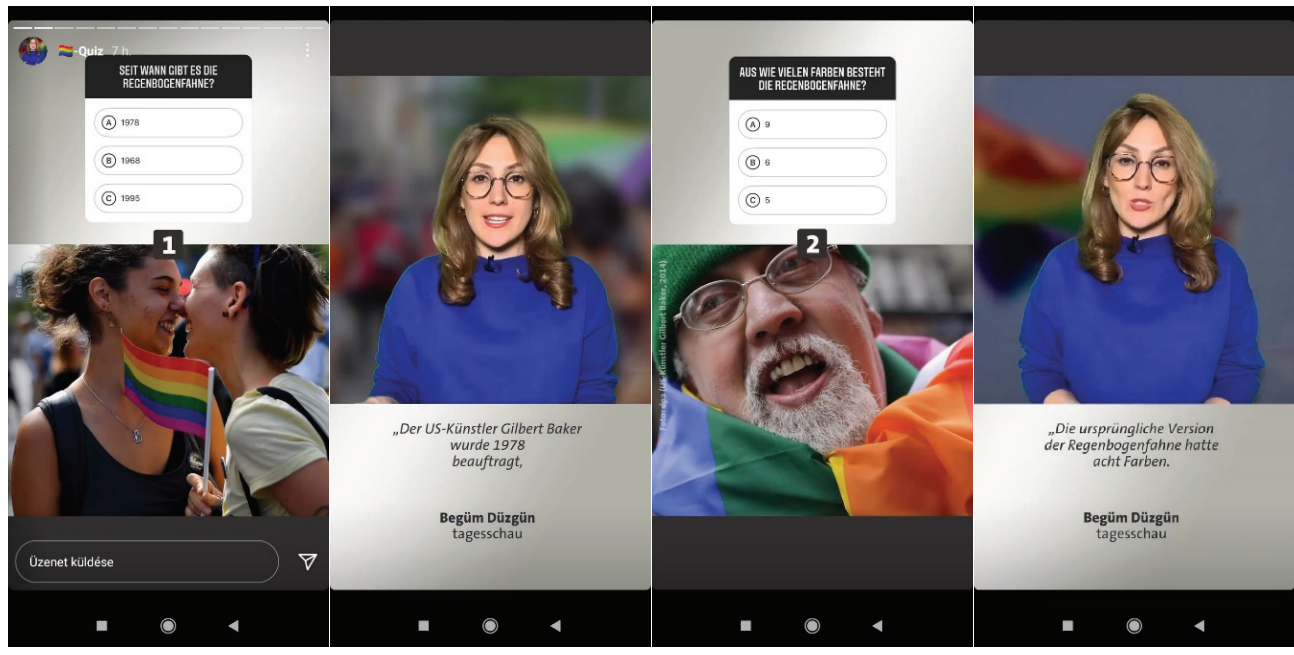

Figure 10. Rainbow flag 
Using the Instagram Story feature, it is also possible to publish various - in this case, educational - quizzes, which allow the users to answer questions and then check if their answer was correct. Since the quiz is interactive, it can further engage readers and increase their loyalty to the news media (Figure 10).

Tagesschau reports the audience about essentially the same news, in the same manner, on all its digital platforms - except some minor fine-tuning. ${ }^{16}$ Their news on their third-party platform accounts are about foreign and domestic politics, current events (e.g. the COVID-19 pandemic, the severe floods in Germany in the summer of 2021, or the Tokyo Olympics), environmental (with a focus on global warming), cultural, and lifestyle issues, education, sports, celebrities, and various other socially relevant topics. When being published, the information is embedded in a journalistic and expert narrative that explains and interprets the facts, offering the audience an immersive experience using the resources of audiovisual storytelling. Through various integrated forms of interactivity (follow, like, comment, reply to stories, react, forward), the audience can engage with the media and actively respond to the content posted.

The digital and social media activity of the tagesschau brand is an excellent example of how a large social media platform (besides its adverse social effects) can also work as a channel for the effective use of public service media in case their platform logic is recognized and adapted to public interest purposes. By allocating the right resources, integrating innovation into daily work, monitoring user and media consumption habits and adapting to these, public media can also succeed in the age of social networks.

\section{Conclusions}

The analysis of tagesschau, a German public service news brand, leads to a number of general conclusions. The example studied above clearly proves that public service news media may also be able to reach young citizens by choosing the right channel. The most appropriate tool for reaching the youth is obviously social media, especially mobile apps. Building a new digital brand is not necessarily required during the digitalization of a traditional public service media. As we have seen in the example presented, it is feasible by extending the already implemented traditional news brand into the digital field. When creating news content, digital journalists and editors have to adapt to the affordances of the platforms in order to make public and political content popular in social media. Developing new journalistic micro-formats fitting well with general trends in the form, style, and use

16 Since most of the users of the TikTok application are still teenagers, the content and the tone of voice on this platform is the kind that may be of interest to them. At the same time, public life and public service are in the focus here as well. 
of social sites is one possible way to attain this. Social media platforms themselves, as well as media content characteristics, user behaviour and needs are constantly and rapidly changing. As a result, the life cycle of journalistic formats adapted to social media platforms is rather short, and a continuous innovation in genre is needed, based on monitoring and analysing trends. However, all this is rather resource-intensive. Social media news production has an effect on newsroom composition as well. New jobs and skills are in need, especially ones related to image editing, data visualization, and traffic data analysis. The popularity of tagesschau's Instagram account proves that social media apps are able to reach the young users with relevant social, political, economic, and environmental news, capturing their attention and interest through the specific affordances of these applications such as interactivity, visual storytelling, personalization, easy access, and speed.

\section{References}

Allan, S. (2013). Citizen Witnessing: Revisioning Journalism in Times of Crisis. Cambridge: Polity Press.

Atton, C.-Hamilton, J. F. (2008). Alternative Journalism. London: Sage.

Boesman, J.-Costera Meijer, I. (2018). “Don't Read Me the News, Tell Me the

Story": How News Makers and Storytellers Negotiate Journalism's Boundaries When Preparing and Presenting News Stories. Official Research Journal of the International Symposium on Online Journalism 8(1): 13-32. <http://isoj.org/wpcontent/uploads/2018/04/FINALISOJ.pdf $>$ [Accessed on 10 September 2021].

Bruns, A. (2008). Blogs, Wikipedia, Second Life, and Beyond. From Production to Produsage. New York: Peter Lang.

Burgess, J.-Green, J. (2009). YouTube: Online Video and Participatory Culture. Cambridge: Polity Press.

Burgess, J.-Hurcombe, E. (2019. Digital Journalism as Symptom, Response and Agent of Change in the Platformed Media Environment. Digital Journalism, $7(3):$ 359-367.

Carlson, M.-Lewis, S. C. (2015). Boundaries of Journalism. Professionalism, Practices and Participation. New York: Routledge.

Castells, M. (2005). A hálózati társadalom kialakulása. Az információ kora I. Budapest: Gondolat.

(2009). Communication Power. Oxford: Oxford University Press.

Djerf-Pierre, M.-Ghersetti, M.-Hedman, U. (2016). Appropriating Social Media. The Changing Uses of Social Media among Journalists across Time. Digital Journalism 4(7): 849-860.

Fuchs, C. (2014). Social Media: A Critical Introduction. London: SAGE. 
Hermida, A.-Mellado, C. (2020). Dimensions of Social Media Logics: Mapping Forms of Journalistic Norms and Practices on Twitter and Instagram. Digital Journalism 8(7): 864-884.

Jenkins, H. (2006). Convergence Culture. Where Old and New Media Collide. New York: University Press.

Jurrat, N. (2011). Mapping Digital Media: Citizen Journalism and the Internet. London: Open Society Foundations. <http://www.ritimo.org/IMG/pdf/Mapping Digital_Media-4.pdf?fbclid=IwAR3eDXxRFPiVsgbZFFYLFHQ-R7kN8hiAF7Wzbb5NCqoXejJ0uCaYHn07LU> [Accessed on 10 September 2021].

Lowe, G. F.-van Den Bulk, H.-Donders, K. (eds.) (2017). Public Service Media in the Networked Society, RIPE@2017. Gothenburg: Nordicom.

Maares, P.-Hanusch, F. (2018). Exploring the Boundaries of Journalism: Instagram Micro-Bloggers in the Twilight Zone of Lifestyle Journalism. Journalism 1-17. Advance Online Publication. DOI: 10.1177/1464884918801400.

Manovich, L. (2017). Instagram and Contemporary Image. http://manovich. net/index.php/projects/instagram-and-contemporary-image [Accessed on 10 September 2021].

Nah, S.-Chung, D. S. (2020). Understanding Citizen Journalism as Civic Participation. New York: Routledge.

Newman, N. et al. (2020). Digital News Report 2020. Oxford: Reuters Institute for the Study of Journalism. <https://reutersinstitute.politics.ox.ac.uk/sites/default/ files/2020-06/DNR_2020_FINAL.pdf> [Accessed on 10 September 2021].

Nyírő, N.-Csordás, T.-Horváth, D. (2012). Mindenki másképp vesz részt. Médiakutató, ősz <https://mediakutato.hu/cikk/2012_03_osz/04_kozonsegreszvetel_marketing> [Accessed on 10 September 2021].

Pavlik, J. V.-Bridges, F. (2013). The Emergence of Augmented Reality (AR) as a Storytelling Medium in Journalism. Journalism \& Communication Monographs 15(1): 4-59.

Perreault, G. P.-Ferrucci, P. (2020). What Is Digital Journalism? Defining the Practice and Role of the Digital Journalist. Digital Journalism 8(10): 1298-1316.

Poell, T.-Borra, E. (2011). Twitter, YouTube, and Flickr as Platforms of Alternative Journalism: The Social Media Account of the 2010 Toronto G20 Protest. Journalism 13(6): 695-713.

Richardson, A. V. (2020). The Coming Archival Crisis: How Ephemeral Video Disappears Protest Journalism and Threatens Newsreels of Tomorrow. Digital Journalism 8(10): 1338-1346.

Salaverría, R. (2019). Digital Journalism: 25 Years of Research. Review Article. El profesional de la información 28(1): e280101, 1-26.

Singer, J. B. et al. (2011). Participatory Journalism. Guarding Open Gates at Online Newspapers. New Jersey: Wiley-Blackwell. 
Stuart, A. (2013). Citizen Witnessing. Revisioning journalism in times of crisis (Key Concepts in Journalism). Cambridge, Malden: Polity Press.

van Dijck, J.-Poell, T. (2013). Understanding Social Media Logic. Media and Communication 1(1): 2-14.

van Dijck, J.-Poell, T.-de Waal, M. (2018). The Platform Society: Public Values in a Connective World. Oxford: Oxford University Press.

Vázquez-Herrero, J.-Direito-Rebollal, S.-López-García, X. (2019). Ephemeral Journalism: News Distribution through Instagram Stories. Social Media + Society. First published on 26 November <https://journals.sagepub.com/ doi/10.1177/2056305119888657> [Accessed on 10 September 2021].

\section{Cite as:}

Glózer, R. (2021). Public Service Media in the Age of Social Networks. Acta Universitatis Sapientiae, Communicatio 8: 1-21. DOI: 10.2478/auscom-2021-0001. 